\title{
INFLUÊNCIA DO ESTADO NUTRICIONAL DE MINICEPAS NO ENRAIZAMENTO DE MINIESTACAS DE EUCALIPTO ${ }^{1}$
}

\author{
Ana Catarina Monteiro Carvalho Mori da Cunha ${ }^{2}$, Haroldo Nogueira de Paiva ${ }^{3}$, Helio Garcia Leite ${ }^{3}$, \\ Nairam Félix de Barros ${ }^{4}$ e Fernando Palha Leite ${ }^{5}$
}

\begin{abstract}
RESUMO - O enraizamento adventício de estacas é influenciado por fatores intrínsecos e extrínsecos do material vegetal. O conhecimento sobre o modo de ação desses fatores sobre o enraizamento é fundamental para o sucesso da produção de mudas por miniestaquia. Entre os fatores envolvidos no enraizamento, pode-se destacar a nutrição mineral, pois existe significativa relação entre ela e o enraizamento. No entanto, a importância de vários nutrientes nesse processo ainda não está totalmente esclarecida. Diante do exposto, o objetivo deste trabalho foi avaliar o grau de associação linear entre o estado nutricional das minicepas com o enraizamento de miniestacas de eucalipto. Foram utilizados dados da empresa CENIBRA, entre os quais se analisaram os de enraizamento de miniestacas e dos teores de nutrientes revelados por análises químicas dos tecidos foliares das minicepas. Os dados usados foram originados de minijardim clonal cultivado em leito de areia, com fertirrigação por gotejamento. Com esses dados, foram realizadas análises para avaliar a existência de correlação linear entre as concentrações de macro e micronutrientes nas minicepas e a taxa de enraizamento das miniestacas. Os resultados indicaram que a nutrição mineral desempenha papel importante no enraizamento adventício das miniestacas produzidas pelas minicepas, gerando respostas diferenciadas de acordo com o nutriente considerado. Os resultados evienciaram que a solução nutritiva aplicada no minijardim clonal deve ser específica para cada clone.
\end{abstract}

Palavras-chave: Propagação vegetativa, Eucalyptus e nutrição mineral.

\section{INFLUENCE OF THE NUTRITIONAL STATUS OF MINISTUMPS ON THE ROOTING OF EUCALYPT MINICUTTINGS}

\begin{abstract}
The adventitious rooting of cuttings is influenced by intrinsic and extrinsic factors of the plant material. The knowledge about the way of the action of these factors upon rooting is essential for the success of the seedling production by minicuttings. Among the factors involved in rooting the mineral nutrition can be emphasized because there is a significant relation between it and rooting, but the importance of various nutrients in this process has not been completely explained yet. Thus, the objective of this work was to evaluate the linear association degree between the nutritional status of ministumps with the rooting of eucalyptus minicuttings. Data from the CENIBRA enterprise were used, and those of rooting of minicuttings and the nutrient contents found in chemical analyses of leaf tissues of the ministumps were analyzed. The data used were from a clonal minigarden grown in sand beds, with fertirrigation by dripping. With these data, analyses were performed to evaluate the existence of a linear correlation among the concentrations of macro and micronutrients in the ministumps and the rooting rate of the minicuttings. The results indicate that the mineral nutrition plays an important role on the adventitious rooting of the minicuttings produced by the ministumps, generating different responses according to the nutrient considered. The results of this study indicate that the nutritive solution used in the clonal minigarden must be specific for each clone.
\end{abstract}

Keywords: Vegetative propagation, Eucalyptus and nutritional nutrition.

\footnotetext{
${ }^{1}$ Recebido em 25.09.2007 e aceito para publicação em 29.05.2009.

${ }^{2}$ Programa de Pós-Graduação em Ciência Florestal da Universidade Federal de Viçosa. E-mail: <catarina_mori@ yahoo.com.br>.

${ }^{3}$ Departamento de Engenharia Florestal da UFV. E-mail: <hnpaiva@ufv.br>.

${ }^{4}$ Departamento de Solos da UFV. E-mail: <nfbarros@ufv.br>.

${ }^{5}$ Celulose Nipo Brasileira S A. E-mail: <fernando.leite@ cenibra.com.br>
} 


\section{INTRODUÇÃO}

A importância do Eucalyptus no cenário atual da silvicultura clonal brasileira tem estimulado consideráveis investimentos em pesquisa, o que vem proporcionando o desenvolvimento da propagação vegetativa (XAVIER et al., 2001). Em silvicultura, a propagação vegetativa tem sido amplamente utilizada para multiplicar indivíduos obtidos por meio de programas de melhoramento ou selecionados de populações naturais (HARTMANN et al., 1997).

A importância de se conhecerem os efeitos dos fatores que afetam a formação de raízes e suas implicações está relacionada ao sucesso ou fracasso da produção de mudas via enraizamento adventício. O enraizamento de espécies lenhosas, mesmo em condições in vitro, é genótipo-dependente. Diferentes espécies, híbridos e, mesmo, diferentes clones do mesmo estoque parental podem requerer diferentes condições de cultivo (MOKOTEDI et al., 2000).

O enraizamento adventício é uma etapa essencial na propagação vegetativa (DE KLERK et al., 1999) de espécies lenhosas economicamente importantes (FETTNETO et al., 2001). Esse é um processo complexo, sendo afetado por diversos fatores, como: hormônios (DE KLERK et al., 1999; WENDLING e XAVIER, 2005; FOGAÇAe FETT-NETO, 2005), compostos fenólicos, características genéticas (WENDLING e XAVIER, 2005), estado nutricional (BELLAMINE et al., 1998; JOSTEN e KUTSCHERA, 1999; SCHWAMBACH et al., 2005), variações nas condições climáticas (WILSON, 1998; FETTNETOetal., 2001; CORRÊAeFETT-NETO, 2004; CORRÊA et al., 2005) e, ainda, respostas associadas ao estresse.

Os maiores obstáculos ao conhecimento dos fenômenos envolvidos no processo de formação de raízes são relativos à dificuldade de isolar e caracterizar os fatores que os controlam, em virtude de sua complexidade e da grande interação entre eles. Entre esses fatores, destaca-se a nutrição mineral (ASSIS e TEIXEIRA, 1998).

Existe significativa relação entre a nutrição mineral e o enraizamento, no entanto, a importância de vários nutrientes nesse processo ainda não está totalmente esclarecida. De modo geral, qualquer nutriente envolvido nos processos metabólicos associados à diferenciação e formação de sistema radicular é considerado essencial para a iniciação radicular (MALAVASI, 1994). Embora o enraizamento de estacas e a nutrição mineral das brotações estejam intimamente relacionados, poucos estudos têm sido conduzidos visando à caracterização dos efeitos de nutrientes específicos (SCHWAMBACH et al., 2005).

Os nutrientes minerais possuem funções essenciais e específicas no metabolismo vegetal: podem agir como constituintes da estrutura orgânica, ativadores de reações enzimáticas, carreadores de cargas e osmorreguladores (MARSCHNER, 1995). O "status" nutricional desempenha papel importante nas fases de indução e de formação de raízes adventícias, gerando respostas diferenciadas tanto em relação aos nutrientes quanto às concentrações testadas (SCHWAMBACH et al., 2005).

De maneira geral, evidencia-se uma carência muito grande de informações sobre a importância de determinados nutrientes, bem como sobre a nutrição das plantas doadoras de propágulos em geral, no processo de iniciação, formação, crescimento e desenvolvimento das raízes adventícias em estacas ou miniestacas.

Diante do exposto, o objetivo deste trabalho foi avaliar a existência de correlação linear entre o estado nutricional de minicepas com o enraizamento de miniestacas de eucalipto, cultivados em minijardim clonal em leito de areia.

\section{MATERIAL E MÉTODOS}

Neste trabalho foi utilizado o banco de dados do viveiro da Celulose Nipo-Brasileira S. A. - CENIBRA, localizada no Município de Belo Oriente, MG. Os dados utilizados foram referentes ao enraizamento das miniestacas e aos teores dos nutrientes revelados pelas análises químicas do tecido foliar das minicepas oriundas do minijardim clonal em leito de areia.

O Município de Belo Oriente, MG, localiza-se na região do Vale do Rio Doce, com clima do tipo Cwa (subtropical, chuvoso e mesotérmico), segundo a classificação de Köeppen, latitude de 19¹8'23" S, longitude de $42^{\circ} 22^{\prime} 46^{\prime \prime} \mathrm{W}$ e altitude média de $363 \mathrm{~m}$. Apresenta precipitação média anual de $1.233 \mathrm{~mm}$, temperatura média anual de $21^{\circ} \mathrm{C}$, com máxima média de $27^{\circ} \mathrm{C}$ e mínima médiade $14^{\circ} \mathrm{C}$ (INSTITUTOBRASILEIRODEGEOGRAFIA E ESTATÍSTICA-IBGE, 1969).

Os dados analisados foram referentes ao período de 2003 a 2005 e incluíram os clones que continham 
maior quantidade de dados disponíveis. Os clones analisados foram: 57, 2719 (clones de Eucalyptus grandis x desconhecido); 129, 7074 (clones de Eucalyptus grandis); 386, 908, 911 e 957 (clones de Eucalyptus urophylla) e 1046, 1128, 1206, 1207, 1213 e 1274 (clones de Eucalyptus grandis x Eucalyptus urophylla). Esses clones constituíam o minijardim clonal oriundo do enraizamento de miniestacas propagadas pelo método da estaquia convencional (XAVIER e WENDLING, 1998).

Os dados foram originados de minijardim clonal cultivado em leito de areia, sob teto translúcido retrátil, com fertirrigação por gotejamento, sendo aplicados $5 \mathrm{~L}$ de solução nutritiva por metro quadrado de minijardim por dia. A fertirrigação foi efetuada através de sistema automatizado, sendo usada a solução nutritiva apresentada na Tabela 1

Para evitar salinização, quinzenalmente foi aplicada uma lâmina de água pura de $10 \mathrm{~mm}$ e a cada dois meses, uma $20 \mathrm{~mm}$. A solução nutritiva-estoque apresentava a condutividade elétrica entre 1,0 e $1,5 \mathrm{mS} . \mathrm{cm}^{-1}$ durante os meses mais quentes do ano e entre 1,5 e 2,0 mS.cm${ }^{1}$ nos meses mais frios. Em todos os nutrientes, permitiuse uma variação de concentração em torno de $10 \%$. $\mathrm{O}$ pH das soluções foi mantido entre 5,5 e 6,5.

A coleta das brotações para preparo de miniestacas foi feita de formas seletiva e contínua, de modo a manter as minicepas em bom estado vegetativo, ou seja, com vigorosa produção de brotos, e com sistema radicular ativo. A periodicidade das coletas era de aproximadamente uma vez por semana. Foram coletadas miniestacas apicais com dimensões variando entre 4 e $6 \mathrm{~cm}$, contendo dois a três pares de folhas, sendo estas reduzidas à metade.

Tabela 1 - Solução nutritiva usada no minijardim clonal de Eucalyptus cultivado em leito de areia

Table 1 - Nutritive solution used in the clonal minigarden of Eucalyptus grown in sand bed

\begin{tabular}{lc}
\hline Fertilizante & Dose $\left({\left.\mathrm{g} 1000 \mathrm{~L}^{-1}\right)}^{-1}\right.$ \\
\hline Nitrato de cálcio & 33.300 \\
Sulfato de Amônio & 13.300 \\
Ácido Fosfórico & 3.300 \\
Cloreto de Potássio & 11.100 \\
Sulfato de Magnésio & 14.400 \\
Ácido Bórico & $1.222,2$ \\
Sulfato de Zinco & 122,2 \\
Sulfato de Cobre & 166,7 \\
Sulfato Ferroso & $3.222,2$ \\
EDTA Dissódico & $4.666,7$ \\
Sulfato de Manganês & 666,7 \\
Molibdato de Sódio & 33,3 \\
\hline
\end{tabular}

Após serem coletadas e preparadas, as miniestacas foram colocadas em tubetes contendo um substrato composto de partes iguais de casca de arroz carbonizada e vermiculita de granulometria grossa. Esse substrato recebeu adição de: $8,0 \mathrm{~kg} \mathrm{~m}^{-3}$ de superfosfato simples; $0,695 \mathrm{~kg} \mathrm{~m}^{-3}$ de sulfato de amônio; $0,208 \mathrm{~kg} \mathrm{~m}^{-3}$ de cloreto de potássio; $0,014 \mathrm{~kg} \mathrm{~m}^{-3}$ de sulfato de zinco; 0,014 $\mathrm{kg} \mathrm{m}^{-3}$ de sulfato de cobre; $0,014 \mathrm{~kg} \mathrm{~m}^{-3}$ de sulfato de manganês; e $0,028 \mathrm{~kg} \mathrm{~m}^{-3}$ de ácido bórico. Os tubetes plásticos tinham capacidade para $50 \mathrm{~cm}^{3}$.

Para o enraizamento, as miniestacas permaneceram em casa de vegetação (umidade relativa do ar e $\geq 80 \%$ ) por um período de 15 a 25 dias, seguindo, posteriormente, para a casa de sombra, com sombrite de $50 \%$, por cinco a sete dias. Na saída da casa de sombra, foi feita uma primeira seleção das mudas, separando-se as enraizadas das não enraizadas e agrupando-as por tamanho. As mudas, de acordo com o tamanho, foram transferidas para bandejas, de modo a preencher $30 \%$ de seus orifícios, e permaneceram em uma área de crescimento por 15 a 20 dias. Ao sair da área de crescimento, foi feita uma segunda seleção das mudas, de modo semelhante à primeira, exceto pela eliminação de brotações laterais, deixando-se apenas um caule. As mudas permaneceram em área de aclimatação por aproximadamente 20 dias até serem expedidas.

Os dados utilizados nas análises estatísticas corresponderam à média mensal das taxas de enraizamento, em porcentagem.

$\mathrm{Na}$ amostragem dos tecidos foliares, obedeceuse às seguintes orientações: foram coletadas folhas totalmente expandidas no terço médio da minicepa em fase de produção; não foi amostrado o pecíolo; evitouse coletar folhas de minicepas recém-colhidas; e as folhas foram lavadas com água destilada antes de serem processadas para análise. Foram coletadas duas amostras compostas em cada clone, em cada oportunidade, sendo em cada amostra utilizadas 10 minicepas. A frequência da coleta de amostras foi mensal nos anos de 2003 e 2004 e bimensal no ano de 2005 .

Após lavagem, as amostras foram colocadas em estufa para secagem a $60^{\circ} \mathrm{C} \pm 5^{\circ} \mathrm{C}$ até peso constante, sendo a seguir moídas. As análises foram feitas, determinando-se $\mathrm{Ca}, \mathrm{Mg}, \mathrm{K}, \mathrm{P}, \mathrm{S}, \mathrm{Zn}, \mathrm{Cu}, \mathrm{Fe}$ e $\mathrm{Mn}$ em extrato nitroperclórico; $\mathrm{N}$ em extrato sulfúrico; e $\mathrm{B}$ em extrato de ácido clorídrico, após a calcinação, de acordo com metodologia descrita por EMBRAPA (1997).

R. Árvore, Viçosa-MG, v.33, n.4, p.607-615, 2009 
Para o pareamento dos dados, foi utilizado um critério temporal, de modo que os dados coletados foram pareados mensalmente para poder estabelecer o grau de associação linear entre as variáveis analisadas. Com os dados de enraizamento das miniestacas e análise química dos tecidos foliares das minicepas, foram realizadas análises para estabelecer o tipo e grau de associação entre concentrações de macro e micronutrientes nas minicepas e a taxa de enraizamento das miniestacas. As hipóteses avaliadas foram:

$$
\begin{aligned}
& H_{0(\mathrm{ij})}: \rho_{X i Y j}=0 \\
& H_{a(i j)}: \text { não } H_{0(i j)}
\end{aligned}
$$

em que:

$\rho_{\mathrm{XiY}}$ : coeficiente de correlação linear entre as variáveis aleatórias $\mathrm{X}_{\mathrm{i}}$ e $\mathrm{Y}_{\mathrm{j}}$;

$\mathrm{j}: 1$ e 2 (\% de enraizamento das miniestacas); e

i: $1,2, \ldots, 11$ (macro e micronutrientes).

Essas hipóteses foram avaliadas pela estatística F e analisadas para níveis de significância de 5\%, 10\% e $15 \%$ de probabilidade.

A Tabela 2 mostra as concentrações de macro e micronutrientes considerados adequados, elevados, baixos e deficientes para brotações de Eucalyptus, com idade entre 7 e 14 dias, em condição de minijardim clonal, segundo Higashi et al. (2004). Esses valores foram usados para discutir os resultados encontrados, contabilizando-se a frequência de casos de concentração dos nutrientes nas minicepas considerados altos, adequados, baixos e deficientes, bem como considerando os dados originais das análises químicas dos tecidos.

\section{RESULTADOS E DISCUSSÃO}

As médias das concentrações de nutrientes nas brotações são apresentadas na Tabela 3 e as correlações entre as concentrações de macro e micronutrientes e as taxas de enraizamento das miniestacas dos clones de Eucalyptus, na Tabela 4.

Em nitrogênio foi observada a correlação negativa significativa do clone 957 e positiva significativa do clone 57. No clone 957, a média do teor de nitrogênio nas brotações encontrava-se em nível considerado alto ao comparar com as concentrações de nutrientes apresentados na Tabela 2, mostrando que redução nos teores de nitrogênio poderia promover maior taxa de enraizamento. No clone 57, a média do teor do nutriente nas brotações estava dentro do nível adequado, e, apesar de estarem próximos do nível elevado, verificouse que aumento nos teores de nitrogênio nas brotações resultaria em incremento nas taxas de enraizamento. Pode-se verificar na Tabela 5 que, para o nitrogênio, a maioria das observações se encontrava dentro de níveis adequados ou altos, o que pode explicar os resultados de correlações serem não significativos na maioria dos clones.

Essa divergência de resultados, de efeitos positivos e negativos do nitrogênio em relação ao enraizamento, também tem sido observada na literatura. Para Hartmann et al. (1997), de modo geral o nitrogênio está correlacionado negativamente com o enraizamento. A porcentagem de enraizamento de microestacas de Eucalyptus globulus foi afetada pela nutrição com nitrato, ou seja, a remoção do amônio e reposição com concentrações moderadas de nitrato revelaram significativo progresso no enraizamento (SCHWAMBACH et al., 2005).

Tabela 2 - Teores dos macro e micronutrientes considerados adequados, acima e abaixo dos adequados e deficientes nas brotações de Eucalyptus com idade entre 7 e 14 dias, em condição de minijardim clonal

Table 2 - Contents of macro and micronutrients considered suitable above and below the suitable and deficient for the

\begin{tabular}{|c|c|c|c|c|c|c|c|c|c|c|c|}
\hline \multirow{3}{*}{$\begin{array}{l}\text { Teor } \\
\text { nutricional }\end{array}$} & \multicolumn{11}{|c|}{ Nutrientes } \\
\hline & $\mathrm{N}$ & $\mathrm{P}$ & $\mathrm{K}$ & $\mathrm{Ca}$ & $\mathrm{Mg}$ & $\mathrm{S}$ & B & $\mathrm{Cu}$ & $\mathrm{Fe}$ & Mn & $\mathrm{Zn}$ \\
\hline & \multicolumn{6}{|c|}{$\mathrm{g} \mathrm{kg}^{-1}$} & \multicolumn{5}{|c|}{$\mathrm{mg} \mathrm{kg}^{-1}$} \\
\hline Alto & $>40$ & $>4$ & $>30$ & $>7$ & $>4$ & $>2,5$ & $>70$ & $>15$ & $>220$ & $>500$ & $>60$ \\
\hline Adequado & $28-40$ & $2,5-4$ & $15-30$ & $5-7$ & $2-3$ & $2-2,5$ & $35-70$ & $8-15$ & $100-220$ & $250-500$ & $30-60$ \\
\hline Baixo & $20-28$ & $1,5-2,5$ & $10-15$ & $3-5$ & $1-2$ & $1,3-2$ & $20-35$ & $5-8$ & $75-100$ & $150-250$ & $20-30$ \\
\hline Deficiente & $<20$ & $<1,5$ & $<10$ & $<3$ & $<1$ & $<1,3$ & $<20$ & $<5$ & $<75$ & $<150$ & $<20$ \\
\hline
\end{tabular}
sprouting of Eucalyptus, between 7 and 14 days of age, in a clonal minigarden condition

Fonte: Higashi et al., 2004.

R. Árvore, Viçosa-MG, v.33, n.4, p.607-615, 2009 
Tabela 3 - Médias das concentrações de macro e micronutrientes nas miniestacas dos clones de Eucalyptus Table 3 -Means of the macro and micronutrient concentrations in the minicuttings of the Eucalyptus clones

\begin{tabular}{|c|c|c|c|c|c|c|c|c|c|c|c|}
\hline \multirow{3}{*}{$\begin{array}{l}\text { Clones } \\
\text { nutricional }\end{array}$} & \multicolumn{11}{|c|}{ Nutrientes } \\
\hline & $\bar{N}$ & $\mathrm{P}$ & $\bar{K}$ & $\mathrm{Ca}$ & $\mathrm{Mg}$ & $\mathrm{S}$ & $\mathrm{Zn}$ & $\mathrm{Cu}$ & $\mathrm{Fe}$ & $\mathrm{Mn}$ & B \\
\hline & & & $\mathrm{g} \mathrm{kg}^{-1}$ & & & & & & $\mathrm{mg} \mathrm{kg}^{-1}$ & & \\
\hline 57 & 39,00 & 3,60 & 23,60 & $\overline{6,80}$ & 3,20 & 1,10 & 34,73 & 13,21 & 102,51 & 1060,64 & 35,63 \\
\hline 129 & 39,30 & 3,40 & 21,90 & 5,30 & 2,90 & 1,50 & 34,60 & 11,21 & 121,75 & 862,82 & 41,22 \\
\hline 386 & 41,60 & 3,90 & 22,30 & 7,90 & 3,40 & 2,00 & 41,26 & 14,02 & 112,38 & 1367,13 & 43,00 \\
\hline 908 & 36,40 & 3,20 & 26,10 & 7,90 & 3,30 & 1,20 & 26,68 & 10,04 & 62,75 & 470,27 & 36,62 \\
\hline 911 & 39,80 & 4,00 & 23,10 & 5,60 & 3,10 & 1,50 & 41,15 & 8,20 & 101,82 & 750,54 & 44,59 \\
\hline 957 & 42,50 & 3,50 & 21,10 & 7,00 & 3,20 & 1,60 & 36,78 & 10,60 & 112,66 & 1065,21 & 42,22 \\
\hline 1046 & 40,70 & 4,00 & 24,40 & 6,30 & 3,30 & 1,60 & 36,55 & 11,04 & 105,35 & 991,57 & 38,17 \\
\hline 1128 & 39,10 & 3,70 & 21,50 & 7,20 & 3,00 & 1,70 & 36,88 & 12,40 & 95,84 & 1258,12 & 38,41 \\
\hline 1206 & 42,80 & 4,10 & 25,10 & 6,30 & 3,10 & 1,60 & 45,42 & 13,24 & 123,00 & 1247,30 & 42,52 \\
\hline 1207 & 39,70 & 3,80 & 22,80 & 6,60 & 3,30 & 1,60 & 37,37 & 11,91 & 112,84 & 1015,12 & 40,99 \\
\hline 1213 & 41,10 & 4,00 & 24,20 & 6,10 & 3,20 & 1,70 & 37,37 & 12,57 & 110,20 & 951,11 & 37,20 \\
\hline 1274 & 41,40 & 4,00 & 25,20 & 6,20 & 3,20 & 1,50 & 38,57 & 11,83 & 119,60 & 1082,94 & 41,21 \\
\hline 2719 & 34,50 & 3,60 & 19,90 & 7,10 & 2,60 & 1,50 & 33,27 & 15,37 & 147,25 & 957,15 & 42,60 \\
\hline 7074 & 37,90 & 3,40 & 18,80 & 6,70 & 2,80 & 1,50 & 35,76 & 10,41 & 110,38 & 1033,97 & 40,87 \\
\hline
\end{tabular}

Tabela 4 - Coeficiente de correlação de Pearson entre as concentrações de nutrientes e o enraizamento das miniestacas dos clones de Eucalyptus

Table 4 - Pearson correlation coefficient among the nutrient concentrations and the rooting of minicuttings of the Eucalyptus clones

\begin{tabular}{|c|c|c|c|c|c|c|c|c|c|c|c|c|c|}
\hline \multirow[t]{2}{*}{ Clones } & \multirow{2}{*}{$\begin{array}{c}\text { Médias de } \\
\text { enraizamento }(\%)\end{array}$} & \multirow{2}{*}{$\begin{array}{l}\text { Númerode } \\
\text { observações }\end{array}$} & \multicolumn{9}{|c|}{ Nutrientes } & \multirow[b]{2}{*}{ Mn } & \multirow[b]{2}{*}{ B } \\
\hline & & & $\mathrm{N}$ & $\mathrm{P}$ & $\mathrm{K}$ & $\mathrm{Ca}$ & $\mathrm{Mg}$ & $\mathrm{S}$ & $\mathrm{Zn}$ & $\mathrm{Cu}$ & $\mathrm{Fe}$ & & \\
\hline 57 & 85,8 & 29 & $0,53^{*}$ & $0,40^{*}$ & $0,47^{*}$ & $-0,43^{*}$ & $0,27^{\text {ns }}$ & $0,30^{* * * *}$ & $0,35^{* *}$ & $0,23^{\mathrm{ns}}$ & $0,40^{*}$ & $0,22^{\mathrm{ns}}$ & $0,15^{\mathrm{ns}}$ \\
\hline 129 & 86,8 & 28 & $0,22^{\mathrm{ns}}$ & $0,28^{\mathrm{ns}}$ & $0,37^{* *}$ & $0,31^{* * *}$ & $0,16^{\mathrm{ns}}$ & $-0,25^{\text {ns }}$ & $-0,18^{\mathrm{ns}}$ & $-0,20^{\mathrm{ns}}$ & $0,07^{\mathrm{ns}}$ & $0,02^{\mathrm{ns}}$ & $0,16^{\mathrm{ns}}$ \\
\hline 386 & 84,4 & 26 & $-0,06^{\mathrm{ns}}$ & $-0,02^{\mathrm{ns}}$ & $0,04^{\mathrm{ns}}$ & $-0,32^{* * *}$ & $0,19^{\text {ns }}$ & $0,00^{\mathrm{ns}}$ & $-0,17^{\mathrm{ns}}$ & $-0,01^{\mathrm{ns}}$ & $0,18^{\mathrm{ns}}$ & $-0,09^{\mathrm{ns}}$ & $-0,04^{\mathrm{ns}}$ \\
\hline 908 & 75,6 & 20 & $0,13^{\mathrm{ns}}$ & $0,07^{\mathrm{ns}}$ & $-0,09^{\text {ns }}$ & $0,10^{\mathrm{ns}}$ & $-0,15^{\text {ns }}$ & $0,10^{\mathrm{ns}}$ & $0,02^{\text {ns }}$ & $-0,07^{\mathrm{ns}}$ & $0,25^{\mathrm{ns}}$ & $0,28^{\mathrm{ns}}$ & $0,12^{\mathrm{ns}}$ \\
\hline 911 & 85,4 & 28 & $-0,15^{\mathrm{ns}}$ & $0,08^{\mathrm{ns}}$ & $-0,20^{\text {ns }}$ & $-0,08^{\mathrm{ns}}$ & $0,07^{\mathrm{ns}}$ & $-0,08^{\mathrm{ns}}$ & $0,02^{\text {ns }}$ & $-0,22^{\mathrm{ns}}$ & $0,10^{\mathrm{ns}}$ & $0,09^{\mathrm{ns}}$ & $0,03^{\text {ns }}$ \\
\hline 957 & 83,0 & 26 & $-0,38^{* *}$ & $-0,11^{\mathrm{ns}}$ & $-0,17^{\mathrm{ns}}$ & $-0,18^{\mathrm{ns}}$ & $0,19^{\text {ns }}$ & $-0,18^{\text {ns }}$ & $0,01^{\mathrm{ns}}$ & $0,07^{\mathrm{ns}}$ & $0,06^{\mathrm{ns}}$ & $-0,01^{\mathrm{ns}}$ & $0,17^{\mathrm{ns}}$ \\
\hline 1046 & 73,2 & 27 & $-0,22^{\mathrm{ns}}$ & $0,05^{\mathrm{ns}}$ & $-0,02^{\text {ns }}$ & $-0,18^{\mathrm{ns}}$ & $0,08^{\mathrm{ns}}$ & $0,14^{\mathrm{ns}}$ & $0,60^{\mathrm{ns}}$ & $0,07^{\mathrm{ns}}$ & $-0,03^{\mathrm{ns}}$ & $0,17^{\mathrm{ns}}$ & $-0,04^{\mathrm{ns}}$ \\
\hline 1128 & 79,5 & 27 & $0,22^{\mathrm{ns}}$ & $0,24^{\mathrm{ns}}$ & $0,00^{\mathrm{ns}}$ & $-0,20^{\mathrm{ns}}$ & $-0,03^{\mathrm{ns}}$ & $0,13^{\mathrm{ns}}$ & $-0,07$ & $0,16^{\mathrm{ns}}$ & $0,23^{\mathrm{ns}}$ & $0,24^{\mathrm{ns}}$ & $0,12^{\mathrm{ns}}$ \\
\hline 1206 & 78,7 & 23 & $-0,25^{\mathrm{ns}}$ & $-0,18^{\mathrm{ns}}$ & $-0,36^{* *}$ & $-0,21^{\mathrm{ns}}$ & $0,32^{* * *}$ & $0,01^{\mathrm{ns}}$ & $0,38^{* *}$ & $0,28^{\mathrm{ns}}$ & $-0,02^{\mathrm{ns}}$ & $0,25^{\mathrm{ns}}$ & $0,33^{* * * *}$ \\
\hline 1207 & 73,0 & 26 & $0,04^{\mathrm{ns}}$ & $0,08^{\mathrm{ns}}$ & $-0,09^{\mathrm{ns}}$ & $-0,51^{*}$ & $0,13^{\mathrm{ns}}$ & $0,28^{\mathrm{ns}}$ & $0,46^{*}$ & $0,23^{\mathrm{ns}}$ & $-0,11^{\mathrm{ns}}$ & $0,44^{*}$ & $0,31^{* * * *}$ \\
\hline 1213 & 79,8 & 28 & $0,09^{\mathrm{ns}}$ & $0,20^{\mathrm{ns}}$ & $-0,03^{\text {ns }}$ & $-0,34^{* *}$ & $0,39^{*}$ & $0,11^{\mathrm{ns}}$ & $0,31^{* * * *}$ & $0,37^{* *}$ & $-0,04^{\mathrm{ns}}$ & $0,17^{\mathrm{ns}}$ & $0,11^{\mathrm{ns}}$ \\
\hline 1274 & 81,3 & 25 & $-0,19^{\mathrm{ns}}$ & $0,09^{\text {ns }}$ & $0,04^{\mathrm{ns}}$ & $-0,28^{\mathrm{ns}}$ & $0,21^{\mathrm{ns}}$ & $0,11^{\mathrm{ns}}$ & $0,26^{\mathrm{ns}}$ & $0,17^{\mathrm{ns}}$ & $-0,13^{\mathrm{ns}}$ & $0,24^{\mathrm{ns}}$ & $0,28^{\mathrm{ns}}$ \\
\hline 2719 & 88,2 & 26 & $-0,06^{\mathrm{ns}}$ & $0,09^{\mathrm{ns}}$ & $-0,05^{\mathrm{ns}}$ & $-0,38^{* *}$ & $0,30^{* * * *}$ & $0,07^{\mathrm{ns}}$ & $0,24^{\text {ns }}$ & $0,27^{\mathrm{ns}}$ & $0,09^{\text {ns }}$ & $0,07^{\mathrm{ns}}$ & $0,33^{* *}$ \\
\hline 7074 & 79,6 & 28 & $-0,24^{\mathrm{ns}}$ & $-0,08^{\mathrm{ns}}$ & $-0,33^{* *}$ & $-0,07^{\mathrm{ns}}$ & $-0,12^{\mathrm{ns}}$ & $-0,06^{\mathrm{ns}}$ & $-0,06^{\mathrm{ns}}$ & $-0,03^{\mathrm{ns}}$ & $0,16^{\mathrm{ns}}$ & $0,25^{\mathrm{ns}}$ & $0,10^{\mathrm{ns}}$ \\
\hline
\end{tabular}

* Significativo em nível de $5 \%$ de probabilidade de erro; ** significativo em nível de $10 \%$ de probabilidade de erro; *** significativo em nível de $15 \%$ de probabilidade de erro; e ns = não significativo.

Em relação ao fósforo, foi observada correlação positiva significativa no clone 57 . Embora a média da concentração desse nutriente tenha sido enquadrada dentro de nível adequado, existe a necessidade da aplicação de maior dose, visando aumentar o enraizamento, contrariando o que foi observado por Anuradha e Marayanan (1991). Esses autores relataram que a deficiência de fósforo aumenta o alongamento de raízes. Bucio et al. (2002) também observaram comportamento semelhante, ou seja, formação de raízes laterais sob deficiência de fósforo. Foi observado no fósforo comportamento semelhante ao do nitrogênio em relação ao número de casos da concentração, de acordo com as faixas de suficiência, ou seja, um balanço entre os níveis alto e adequado (Tabela 5), explicando as correlações não significativas.

No potássio, foram constatadas correlações significativas positivas e negativas, estando as médias de concentrações do nutriente dentro de níveis considerados adequados, em todos os clones 
(Tabela 5). Essa diferença entre correlações positivas e negativas dentro de um nível semelhante de nutrição pode ser atribuída à influência do material genético. Nos clones 1206 e 7074, é necessária diminuição das dosagens de potássio, visando aumentar os índices de enraizamento; clones 57 e 129, o indicado é aumentar a dose desse nutriente. Nesse sistema de cultivo e sob as condições de nutrição analisadas, foram observadas correlações significativas, indicando que as faixas de concentrações que são consideradas adequadas por Higashi et al. (2004) não se aplicam a todos os clones estudados.

O cálcio é requerido na elongação e divisão celular, no entanto as altas concentrações observadas nos brotos traduziram-se em efeitos negativos significativos para o enraizamento, nos clones 57, 386, 1207, 1213 e 2719. Somente no clone 129 foi verificada correlação positiva significativa, sendo as brotações com concentrações próximas de baixa para o nutriente. De modo geral, no cálcio as concentrações empregadas são prejudiciais ao enraizamento, sendo uma redução na aplicação favorável ao enraizamento, exceto no clone 129.

Segundo Bellamine et al. (1998), o cálcio é um dos poucos minerais que influenciam individualmente de forma marcante o enraizamento. A frequência de casos da concentração de acordo com a faixa de suficiência para cálcio revelou, de modo geral, um balanço entre os níveis adequados e altos (Tabela 5). Ainda, observouse ampla variação nas concentrações do nutriente, indicando ser necessários mais estudos que visem explicar o papel do cálcio no enraizamento adventício.

Foram verificadas correlações positivas significativas do magnésio nos clones 1206 e 2719, indicando a necessidade de aumento da dose de magnésio para o enraizamento das miniestacas. O papel do magnésio durante a iniciação, crescimento e desenvolvimento radicular ainda não é claro, de forma que os dados encontrados na literatura não são suficientes para que se possam tirar conclusões mais claras. Em todos os clones, foi observada grande frequência de casos dentro de níveis adequados (Tabela 5), o que poderia explicar as correlações não significativas, indicando que o manejo do minijardim, em relação ao magnésio, está sendo realizado de maneira adequada, necessitando de ajustes somente nos clones 1206 e 2719, pois esses clones se mostraram mais exigentes ao nutriente.

R. Árvore, Viçosa-MG, v.33, n.4, p.607-615, 2009

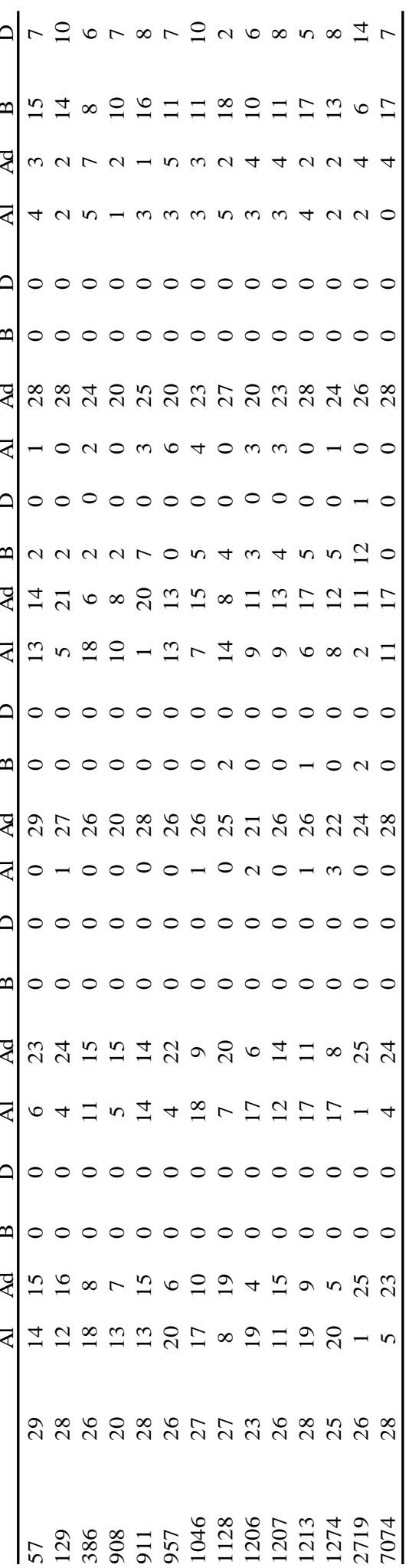


No enxofre, foi verificada correlação positiva significativa no clone 57 , estando as médias das concentrações em níveis considerados deficientes. Dessa forma, efeito positivo no enraizamento ocorreria com o aumento nos teores de enxofre. Pode-se observar que, no enxofre, maior número de casos é encontrado nos níveis baixo e deficiente (Tabela 5), indicando que os teores ideais de enxofre nas miniestacas visando a um enraizamento satisfatório estão no limite entre deficiente e baixo.

Observou-se que o zinco influenciou, positiva e significativamente, o enraizamento dos clones 57, 1206, 1207 e 1213, indicando a necessidade de incremento nas doses de zinco para obter aumento nas taxas de enraizamento, mesmo as miniestacas estando com teores adequados do nutriente. De modo geral, observouse maior frequência de casos dentro de níveis adequados (Tabela 6) para zinco, o que pode explicar os casos de correlações não significativas. Esses resultados indicam que as faixas de concentrações consideradas adequadas pela literatura não se aplicam a todos os clones e a todas as situações, sendo necessário o estabelecimento de níveis adequados para cada clone.

Segundo Hartmann et al. (1997), o aumento dos níveis endógenos de ácido indolacético (AIA) pode ser favorecido pelo zinco, por meio de seu efeito no aumento da produção de triptofano, precursor natural do AIA e de substâncias de reserva, justificando as correlações encontradas entre os teores de zinco e as taxas de enraizamento.

Em experimento conduzido por Schwambach et al. (2005), a porcentagem de enraizamento de microestacas de Eucalyptus globulus foi influenciada por zinco, em parte devido aos efeitos de tratamentos externos, nos quais a concentração de zinco foi deficiente. Verificouse que a remoção do zinco resultou em decréscimo na porcentagem de enraizamento, quando comparadas nas concentrações de $30 \mathrm{mM}$ e $60 \mathrm{mM}$ de zinco.

Em cobre, constataram-se correlações positivas significativas entre o teor do nutriente e o enraizamento do clone 1213. Esse resultado mostra que existe necessidade de aumento da dose desse nutriente para aumentar a porcentagem de enraizamento das miniestacas. Em todos os clones foi verificada maior frequência de casos de concentração na faixa considerada adequada de cobre (Tabela 6), o que pode explicar as correlações não significativas, indicando que os teores desse nutriente que vêm sendo empregado pela empresa são satisfatórios, exceto no clone 1213.

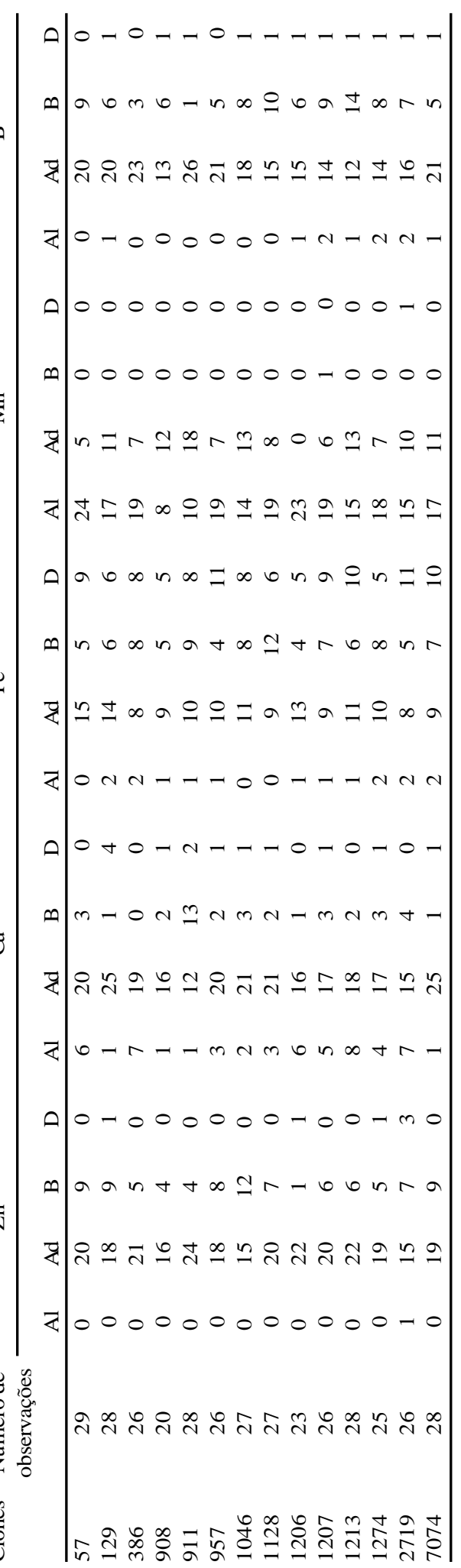

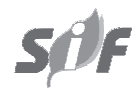

R. Árvore, Viçosa-MG, v.33, n.4, p.607-615, 2009 
O aumento no teor de ferro favoreceu positiva e significativamente o enraizamento das miniestacas no clone 57, apesar de a concentração do nutriente estar em nível adequado, observando-se necessidade de aumentar a dose de ferro para o consequente aumento do enraizamento. No ferro foi verificada, de modo geral, grande dispersão na frequência de casos das faixas de suficiência (Tabela 6), indicando a necessidade de maiores estudos para adequar um protocolo eficiente de adubação para esse nutriente.

O ferro está relacionado à atividade de peroxidases, enzimas envolvidas no crescimento e expansão celulares, diferenciação e desenvolvimento, catabolismo de auxina e lignificação (FANG e KAO, 2000), o que pode explicar o resultado observado no clone 57 .

Verificou-se efeito positivo significativo das concentrações de manganês no enraizamento das miniestacas do clone 1207. Pode-se inferir que existe necessidade de aumentar as doses de manganês nesse clone. Houve balanço entre os níveis adequado e alto dos teores de manganês nas brotações (Tabela 6), o que explica as correlações não significativas.

Em relação à influência do manganês no enraizamento adventício em mudas de abacateiro (Persea americana), foi verificado que as estacas de cultivares de difícil enraizamento apresentavam maiores níveis do nutriente nos tecidos foliares que os cultivares de fácil enraizamento (REUVENI e RAVIV, 1981).

O boro exerceu influência positiva significativa nos clones 1206,1207 e 2719 . Os resultados permitem afirmar que existe necessidade de aumentar a dose de boro, originando consequente aumento nas taxas de enraizamento nesses clones. Houve maior frequência de casos de concentrações dentro de níveis adequados para todos os clones (Tabela 6). Esses resultados indicam que existe faixa adequada para cada clone e explicam as correlações não significativas observadas.

Os efeitos positivos do boro em relação ao enraizamento podem estar relacionados ao fato de que este nutriente faz parte da síntese do RNA e atua no processo de divisão celular (MALAVASI, 1994). Considerando o papel de boro na divisão e expansão celulares, o nutriente tem sido usado para o enraizamento de algumas espécies, como: Actidina deliciosa (ONO et al., 1998) e Helianthus annuus (JOSTEN e KUTSCHERA, 1999), demonstrando que a sua presença favorece a formação de raízes.

\section{CONCLUSÃO}

Com base nos resultados, as seguintes tendências podem ser apontadas:

- A nutrição mineral desempenha papel importante no enraizamento adventício de modo genótipodependente, gerando respostas diferenciadas, de acordo com o nutriente e o clone.

- O manejo do minijardim clonal deve ser mudado, de forma a ser usada uma solução nutritiva específica para cada clone. Dessa forma, será possível utilizar todo o potencial de enraizamento das miniestacas.

- As faixas de concentrações de nutrientes nas brotações consideradas adequadas na literatura não se enquadram a muitos clones estudados. Dessa forma, devem ser conduzidos novos estudos visando definir níveis adequados dos nutrientes estudados, nas miniestacas dos clones de Eucalyptus, de acordo com cada clone especificamente; assim, as soluções nutritivas usadas no sistema de cultivo estudado devem ser remanejadas.

\section{AGRADECIMENTOS}

À Capes, pela bolsa de estudo; ao CNPq, pela bolsa de produtividade em pesquisa; e à Celulose NipoBrasileira S.A. - CENIBRA, pela concessão do banco de dados usados neste trabalho.

\section{6 - REFERÊNCIAS}

ANURADHA, M.; NARAYANAN, A. Promotion of root elongation by phosphorus deficiency. Plant and Soil, v.136, n.2, p. 273-275, 1991.

ASSIS, T. F.; TEIXEIRA, S. L. Enraizamento de plantas lenhosas. In: TORRES, A. C.; CALDAS, L. S.; BUSO, J. A. Cultura de tecidos e transformação genética de plantas. Brasília: Empresa Brasileira de Pesquisa Agropecuária, 1998. v.1.p.261-296.

BELLAMINE, J. et al. Confirmation of the role of auxin and calcium in the late phases of adventitious root formation. Plant Growth Regulation, v.26, NUMERO, p.191-194, 1998.

BUCIO, J. L. et al. Phosphate availability alters architecture and causes changes in hormone sensitivity in the Arabidopsis root system. Plant Physiology, v.129, n.1, p.244-256, 2002. 
CORRÊA, L. R.; FETT-NETO, A. G. Effects of temperature on adventitious root development in microcuttings of Eucaltptus saligna Smith and Eucaltptus globulus Labill. Journal of Thermal Biology, v.29, n.6, p.315-324, 2004.

CORRÊA, L.R. et al. Carbohydrates as regulatory factors on the rooting of Eucalyptus saligna Smith and Eucalyptus globulus Labill. Plant Growth Regulation, v.45, n.1, p.63-73, 2005.

DE KLERK, G. J.; van der KRIEKEN, W.; DE JONG, J. G. Review - The formation of adventitious roots: New concepts, new possibilities. In Vitro Cellular \& Developmental Biology Plant, v.35, n.3, p.189-199, 1999.

\section{EMPRESA BRASILEIRA DE PESQUISA} AGROPECUÁRIA - EMBRAPA. Serviço Nacional de Levantamento e Conservação de Solos. Manual de métodos de analise de solo. Rio de Janeiro: SNLCS, 1997. 212p.

FANG, W. C.; KAO, C. H. Enhanced peroxidase activity in rice leaves in response to excess iron, copper anda zinc. Plant Science, v.158, n.1, p.71-76, 2000.

FETT-NETO, A. G. et al. Distinct effects of auxin and light on adventitious root development in Eucalyptus saligna and Eucalyptus globulus. Tree Physiology, v.21, n.7, p.457-464, 2001.

FOGAÇA, C. M.; FETT-NETO, A. G. Role of auxin and its modulators in the adventitious rooting of Eucalyptus species differing in recalcitrance. Plant Growth Regulation, v.45, n.1, p.1-10, 2005.

HARTMANN, H. T. et al. Plant propagation: principles and practices. 6.ed. New Jersey: Prentice-Hall, 1997. 770p.

HIGASHI, E. N.; SILVEIRA, R. L. V. A.; GONÇALVES, A. N. Nutritional monitoring and fertilization in clonal macro-, mini-, and microgardens. In: GONÇALVES, J. L. M.; BENEDETI, V. (Eds.). Forest nutrition and fertilization. Piracicaba: IPEF, 2004. p.195-221.

INSTITUTO BRASILEIRO DE GEOGRAFIA E ESTATISTICA - IBGE. Enciclopédia dos municípios brasileiros. Rio de Janeiro: 1969. v.27. 459p.
JOSTEN, P.; KUTSCHERA, U. The micronutrient boron causes the development of adventitious roots in sunflower cuttings. Annals of Botany, v.84, n.3, p.337-342, 1999.

MALAVASI, U. C. Macropropagação vegetativa de coníferas - perspectivas biológicas e operacionais. Floresta e Ambiente, v.1, n.1, p.131-35, 1994.

MARSCHNER, H. Mineral nutrition of higher plants. London: Academic Press, 1995. 889p.

MOKOTEDI, M. E. O. et al. In vitro rooting and subsequent survival of two clones of cold-tolerant Eucalyptus grandis X Eucalyptus nitens Hybrid. Hortscience, v.35, n.6, p.1163-1165, 2000.

ONO, E. O.; RODRIGUES, J. D.; PINHO, S. Z. Efeito de auxinas e boro no enraizamento de estacas caulinares de Kiwi retiradas em diferentes épocas. Pesquisa Agropecuária Brasileira, v.33, n.2, p.213-219, 1998.

REUVENI, O.; RAVIV, M. Importance of leaf retention to rooting of avocado cuttings. Journal of the American Society for Horticultural Science, v.106, p. 127-130, 1981.

SCHWAMBACH, J.; FADANELLI, C.; FETT-NETO, A. G. Mineral nutrition and adventitious rooting in microcuttings of Eucalyptus globulus. Tree Physiology, v.25, n.4, p.487-494, 2005.

WENDLING, I.; XAVIER, A. Influência do ácido indolbutírico e ds miniestaquia seriada no enraizamento e vigor de miniestacas de clones de Eucalyptus grandis. Revista Árvore, v.29, n.6, p.921-930, 2005.

WILSON, P. J. Environmental preferences of Eucalyptus globulus stem cuttings in one nursery. New Zealand Journal of Forestry Science, v.28, n.3, p.304-315, 1998.

XAVIER, A.; WENDLING, I. Miniestaquia na clonagem de Eucalyptus. Viçosa, MG: SIF, 1998. 10p.

XAVIER, A. et al. Desempenho do enraizamento de microestacas e miniestacas de clones híbridos de Eucalyptus grandis. Revista Árvore, v.25, n.4, p.403-411, 2001.

R. Árvore, Viçosa-MG, v.33, n.4, p.607-615, 2009 